\title{
Physio-pathological effects of alcohol on the cardiovascular system: its role in hypertension and cardiovascular disease
}

\author{
Yuhei Kawano
}

Alcohol has complex effects on the cardiovascular system. The purpose of this article is to review physio-pathological effects of alcohol on cardiovascular and related systems and to describe its role in hypertension and cardiovascular disease. The relationship between alcohol and hypertension is well known, and a reduction in the alcohol intake is widely recommended in the management of hypertension. Moreover, alcohol has both pressor and depressor actions. The latter actions are clear in Oriental subjects, especially in those who show alcohol flush because of the genetic variation in aldehyde dehydrogenase activity. Repeated alcohol intake in the evening causes an elevation in daytime and a reduction in nighttime blood pressure (BP), with little change in the average 24-h BP in Japanese men. Thus, the hypertensive effect of alcohol seems to be overestimated by the measurement of casual BP during the day. Heavy alcohol intake seems to increase the risk of several cardiovascular diseases, such as hemorrhagic stroke, arrhythmia and heart failure. On the other hand, alcohol may act to prevent atherosclerosis and to decrease the risk of ischemic heart disease, mainly by increasing HDL cholesterol and inhibiting thrombus formation. A J- or U-shaped relationship has been observed between the level of alcohol intake and risk of cardiovascular mortality and total mortality. It is reasonable to reduce the alcohol intake to less than $30 \mathrm{ml}$ per day for men and $15 \mathrm{ml}$ per day for women in the management of hypertension. As a small amount of alcohol seems to be beneficial, abstinence from alcohol is not recommended to prevent cardiovascular disease.

Hypertension Research (2010) 33, 181-191; doi:10.1038/hr.2009.226; published online 15 January 2010

Keywords: alcohol; blood pressure; cardiovascular disease

\section{INTRODUCTION}

Alcohol has complex effects on the cardiovascular system. The relationship between alcohol and hypertension is well known, and a restriction of alcohol intake is widely recommended as a part of lifestyle modifications in the management of hypertension. ${ }^{1-6}$ Alcohol has both pressor and depressor actions, however, and the genetic susceptibility regarding alcohol metabolism influences the cardiovascular effect of alcohol. ${ }^{3,7}$ The effect of alcohol on blood pressure (BP) is also modified by several factors, such as the level of consumption, time period after the last drink and overall drinking behavior.

Alcohol consumption is associated with several cardiovascular diseases, such as brain hemorrhage, heart failure and arrhythmia, as well as with other disorders. ${ }^{3,8-11}$ Heavy drinking and alcoholism not only lead to medical problems but are also serious social concerns. However, alcohol also seems to have beneficial effects, including the prevention of ischemic heart disease. It has been shown that cardiovascular and all-cause mortality is lower in light drinkers compared with nondrinkers. ${ }^{3,8-12}$

The purpose of this article is to review physio-pathological effects of alcohol on cardiovascular and related systems and to describe its role in hypertension and cardiovascular disease. I will outline the cardiovascular actions of alcohol, the effects of alcohol on BP and hypertension, including changes in 24-h BP, and the relationship between alcohol and cardiovascular diseases.

\section{CARDIOVASCULAR ACTIONS OF ALCOHOL}

Acute effect on BP

The effect of a single intake of alcohol on BP in normal subjects is not consistent among studies. Some studies have shown an increase in $\mathrm{BP},{ }^{13,14}$ whereas it decreased ${ }^{15,16}$ or remained unchanged ${ }^{17,18}$ in others. In hypertensive patients, the BP also became elevated ${ }^{19}$ or fell ${ }^{20}$ after a single ingestion of alcohol.

In studies showing the pressor effect of alcohol, a BP increase was observed within $1 \mathrm{~h}$ after drinking; however, the increase was not sustained. ${ }^{3}$ On the other hand, BP usually fell or remained unchanged after alcohol consumption in studies with prolonged observation periods. Stott et al. ${ }^{21}$ reported that BP levels increased at $1 \mathrm{~h}$ after drinking but tended to decrease over the next $7 \mathrm{~h}$ in normotensive subjects.

We examined the effect of a single intake of alcohol $\left(1 \mathrm{ml} \mathrm{kg}^{-1}\right)$ on BP using ambulatory BP monitoring (ABPM) in hypertensive 
Japanese men. ${ }^{7}$ As shown in Figure 1, the BP decreased and the heart rate increased for several hours after drinking alcohol. This alcoholinduced hypotension was marked in subjects showing facial flush identified by visual inspection after drinking, and was mild in those who did not show such flush. A transient pressor response to alcohol consumption was not observed in our study, and BP values the day after drinking were comparable to those on the control day.

Minami et al..$^{22}$ also studied the effect of a single intake of alcohol on ambulatory BP in normotensive and hypertensive Japanese men in relation to the genotype of aldehyde dehydrogenase 2 (ALDH2). In their study, BP decreased significantly after alcohol ingestion in the inactive ALDH2 group (heterozygotes and a homozygote for $\mathrm{ALDH} 2{ }^{\star} 2$ ), whereas the reduction in BP was small but significant only for diastolic BP in the active ALDH2 group (homozygotes for ALDH $2 * 1)$

A single intake of alcohol therefore mainly acts to lower the BP, at least in Japanese men. As this depressor effect varies according to race and the presence and absence of alcohol flush, genetic variation in ALDH2 activity seems to have a major function. It has been shown that subjects with the ALDH2*2 genotype, which is common in Mongoloids but rare in Caucasians and Africans, show facial flush after drinking alcohol because of the accumulation of vasodilative acetaldehyde. ${ }^{3,22-24}$ The mechanisms causing a transient pressor response to alcohol are not clear. An emotional change or gastric
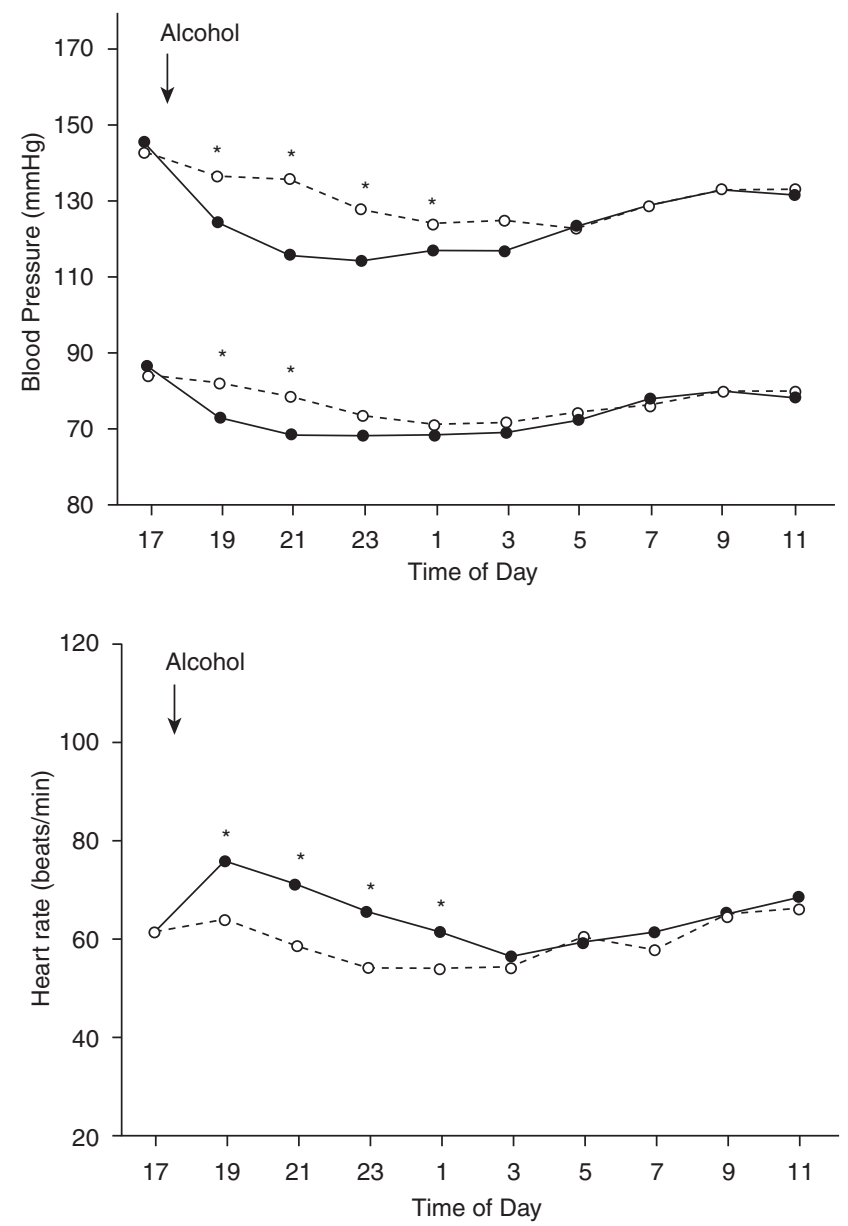

Figure 1 Ambulatory blood pressure (BP) and heart rate during the alcohol intake day $(\bullet)$ and the control day $(O) .{ }^{*}: P<0.05$ between the two periods (adopted from Kawano et al. ${ }^{7}$ with permission). irritation rather than a direct effect of alcohol, however, may be involved in the pressor response because it takes several hours for blood alcohol to disappear after a single intake. ${ }^{3,21}$

\section{Vascular actions}

The action of alcohol on the vasculature is variable according to its concentration and the kind of blood vessel. ${ }^{25,26}$ High concentrations of alcohol constrict most blood vessels. This vasoconstriction depends on calcium ions and is inhibited by calcium channel blockers. Alcohol also acts to augment the vasoconstriction caused by catecholamines and vasopressin and inhibits endothelium-dependent vasodilation. ${ }^{27,28}$ It has been suggested that endothelin and nitric oxide are involved in alcohol-induced vasoconstriction. ${ }^{29}$ Soardo et al. ${ }^{30}$ observed that alcohol increased the levels of endothelin-1, nitric oxide, plasminogen activator inhibitor-1 and oxidative stress both in vivo and in vitro. As the scavengers of oxidants prevented those changes, oxidative stress may have a role in the alcohol-induced endothelial dysfunction. ${ }^{30}$ It was, however, reported that the flowmediated dilation of the brachial artery and blood markers of endothelial function were similar between the usual drinking period and the alcohol restriction period in healthy men. ${ }^{31}$

On the other hand, low concentrations of alcohol usually dilate blood vessels. ${ }^{25,26}$ This effect also seems to be mediated by calcium ions and endothelium-derived nitric oxide. It has been shown that low doses of alcohol increase the release of nitric oxide and augment endothelium-dependent vasodilation. ${ }^{32}$ Criscione et al. ${ }^{27}$ reported that ethanol inhibits norepinephrine-induced vasoconstriction in the rat mesenteric artery. They also observed that norepinephrine-induced vasoconstriction is enhanced after the withdrawal of alcohol. These results seem to be consistent with the time-dependent BP changes after alcohol consumption in humans.

Acetaldehyde, a metabolite of alcohol, acts as a vasodilator. ${ }^{17}$ Subjects with low-active aldehyde dehydrogenase (ALDH2*2) show facial flush after alcohol ingestion because of the accumulation of acetaldehyde in the blood. Such subjects, especially those homozygous for the ALDH2 ${ }^{\star} 2$ genotype, show marked tachycardia and hypotension after alcohol consumption. ${ }^{3,23}$

In our study, the alcohol-induced BP reduction in hypertensive patients was due to a decrease in peripheral vascular resistance (Table 1). ${ }^{7}$ We also observed that the intracellular sodium concentration in red blood cells decreases after alcohol ingestion. ${ }^{33}$ This change may also act to dilate blood vessels through a decrease in the intracellular calcium concentration.

Table 1 Hemodynamic variables after alcohol intake in hypertensive patients (adopted from Kawano et al. with permission)

\begin{tabular}{|c|c|c|c|c|}
\hline \multirow[b]{2}{*}{ Variables } & \multicolumn{2}{|c|}{ Control day } & \multicolumn{2}{|c|}{ Alcohol intake day } \\
\hline & $5 P M$ & $7 P M$ & $5 P M$ & $7 P M$ \\
\hline $\mathrm{MBP}(\mathrm{mm} \mathrm{Hg})$ & $109 \pm 4$ & $100 \pm 4$ & $106 \pm 5$ & $89 \pm 3^{*} \dagger$ \\
\hline HR (b.p.m.) & $54 \pm 2$ & $56 \pm 2$ & $52 \pm 3$ & $68 \pm 5^{*}+$ \\
\hline $\mathrm{Cl}\left(\mathrm{Imin}-1 \mathrm{~m}^{-1}\right)$ & $2.6 \pm 0.2$ & $2.9 \pm 0.3$ & $2.6 \pm 0.2$ & $3.3 \pm 0.3^{*} \dagger$ \\
\hline PVR (dyn s ${ }^{-1} \mathrm{~cm}^{-5}$ ) & $2061 \pm 208$ & $1791 \pm 225$ & $2096 \pm 268$ & $1305 \pm 114^{*} \dagger$ \\
\hline LVFS (\%) & $34 \pm 2$ & $37 \pm 2$ & $35 \pm 1$ & $43 \pm 2 * \dagger$ \\
\hline LVESWS $\left(10^{3}\right.$ dyn $\left.\mathrm{cm}^{-2}\right)$ & $67 \pm 10$ & $56 \pm 7$ & $62 \pm 5$ & $37 \pm 5^{*} \dagger$ \\
\hline
\end{tabular}

Abbreviations: b.p.m., beats per minute; $\mathrm{Cl}$, cardiac index; HR, heart rate; LVESWS, left ventricular end-systolic wall stress; LVFS, left ventricular fractional shortening; MBP, mean blood pressure; PVR, peripheral vascular resistance.

${ }^{\star} P<0.05$ vs. the control day, ${ }^{\dagger} P<0.05$ vs. $5 \mathrm{PM}$ on the alcohol intake day. 
Taken together, alcohol has both constrictive and dilative actions on blood vessels, and these effects may be dependent on race, the dose and timing of alcohol consumption.

\section{Cardiac actions}

The effects of alcohol on the heart are also complex. ${ }^{3,8,34}$ It has been shown that alcohol directly inhibits the contractility of cardiac muscle in a dose-dependent manner. ${ }^{18,26}$ This negative inotropic action is apparent in the isolated heart or after blocking of the autonomic nervous system. ${ }^{18}$

Cardiac function, however, does not often change or even increase after the administration of alcohol in normal humans and animals. Kupari et $a l .^{23}$ reported that both the heart rate and cardiac output increased whereas systemic vascular resistance decreased after alcohol ingestion in healthy volunteers. ${ }^{15}$ They also observed that those changes were small in subjects who did not show facial flush, but were marked in subjects who showed flush after drinking. In our study, the heart rate and cardiac output also increased significantly after alcohol ingestion in hypertensive patients ${ }^{7}$ (Table 1 ). The activation of the sympathetic nervous system seems to mask the direct inhibitory action of alcohol on the heart. Indeed, we have observed that the alcohol-induced increases in heart rate and cardiac output are attenuated after the administration of a beta blocker. ${ }^{35}$

The adverse influence of alcohol on the heart is clear after the consumption of large amounts for many years. It has been shown that the total alcohol intake is positively related to the left ventricular mass and negatively related to the left ventricular ejection fraction. ${ }^{36}$ Structural changes in cardiac muscle were also observed in heavy drinkers ${ }^{37}$ as well as in ethanol-fed rats. ${ }^{38}$ These changes may be involved in alcohol-induced cardiomyopathy, heart failure and arrhythmia.

\section{Alcohol withdrawal syndrome}

Chronic heavy drinkers, such as alcoholic patients, show alcohol withdrawal syndrome, which is characterized by psycho-neurological symptoms and signs after the sudden cessation of alcohol consumption. This syndrome includes elevation of the BP and heart rate because of activation of the sympathetic nervous system. ${ }^{26}$ The pressor response during alcohol withdrawal reaches a peak the day after cessation. ${ }^{39}$ In this case, the BP decreased to a lower level compared with baseline within several days after alcohol withdrawal in heavy drinkers. ${ }^{40}$ As habitual drinkers experience a mild degree of repeated alcohol withdrawal in daily life, it is possible that this withdrawal phenomenon contributes to alcohol-related hypertension.

\section{NEUROHORMONAL ACTIONS OF ALCOHOL}

\section{Actions on the autonomic nervous system}

It has been shown that alcohol activates the sympathetic nervous system. ${ }^{3,26}$ Van de Borne et al. ${ }^{41}$ observed an increase in muscle sympathetic nerve activity after a single intake of alcohol in normal men. In their study, BP did not change, although the heart rate increased significantly. In our study, plasma catecholamines increased but BP decreased after alcohol ingestion in hypertensive patients, and the increase in plasma catecholamines was more pronounced in subjects with a large BP reduction. ${ }^{7,42}$ These results suggest that the activation of the sympathetic nervous system occurs in response to $\mathrm{BP}$ change and acts to compensate for any further BP reduction.

Experimental studies have shown that alcohol suppresses the baroreceptor reflex. ${ }^{43}$ Narkiewicz et al. ${ }^{44}$ reported that alcohol enhances the hypotension induced by lower body negative pressure. The combination of impairment of the baroreceptor reflex and systemic vasodilation acts to potentiate orthostatic hypotension and may induce syncope after drinking in susceptible subjects.

\section{Actions on the endocrine system}

It is known that alcohol increases plasma renin activity. ${ }^{7,26,42}$ As the increase in renin activity was suppressed by pretreatment with propranolol in our study, ${ }^{35}$ it seems to be mediated by the sympathetic nervous system. Alcohol also stimulated the release of adrenocorticotropic hormone, and increases in plasma cortisol and aldosterone were observed after drinking. ${ }^{26}$ It has been reported that dexamethasone inhibited the BP elevation and sympathetic activation after alcohol ingestion. ${ }^{45}$ We and others, however, have failed to observe significant changes in adrenocorticotropic hormone, cortisol or aldosterone. ${ }^{21,42}$

Alcohol suppresses the release of vasopressin; however, this change does not seem to mediate the acute depressor effect of alcohol. ${ }^{21,26,42}$ Several depressor hormones and substances, such as atrial natriuretic peptide, prostaglandin $\mathrm{E}_{2}$, beta endorphin and cyclic GMP, did not change after alcohol ingestion. ${ }^{42}$ Although data relating alcohol intake to plasma atrial natriuretic peptide have been inconsistent, Djousse et al. ${ }^{46}$ observed a positive relationship after adjusting for several confounding factors.

The level of plasma insulin increases after alcohol intake; however, the change is less than that induced by an isocaloric control drink. ${ }^{42}$ It has been shown that a light-to-moderate intake of alcohol enhances insulin sensitivity ${ }^{47}$ and reduces the risk of type 2 diabetes mellitus. ${ }^{48}$ Alcohol therefore seems to have a beneficial effect on insulin and glucose metabolism.

Taken together, alcohol causes various changes in the autonomic nervous system and endocrine system, but these changes do not seem to have a major role in the pressor or depressor effect of alcohol except in the case of alcohol withdrawal syndrome.

\section{ACTIONS OF ALCOHOL ON WATER AND ELECTROLYTE METABOLISM}

Alcohol also exhibits actions on water and electrolyte metabolism. Urinary excretion increases after alcohol ingestion. ${ }^{49,50}$ The increase in urine volume seems to be caused by fluid intake and the suppression of vasopressin. . $^{21,27}$

We have studied the effect of repeated alcohol intake for 7 days on the urine volume and sodium excretion in hypertensive patients. ${ }^{51}$ Urine volume increased on days 3-5 but not on day 1 . Urinary sodium excretion decreased in the early phase but increased in the late phase. The average BP also decreased in the early phase and then returned toward the baseline levels. The initial BP reduction may mask the alcohol-induced diuresis and causes sodium retention, which may be involved in subsequent BP elevation.

It has been shown that urinary potassium excretion decreases after alcohol ingestion. ${ }^{48,49}$ In our study, the serum potassium level decreased after a single intake of alcohol. 7,35 This change in serum potassium seems to be mediated by the sympathetic nervous system, as propranolol attenuated alcohol-induced hypokalemia. ${ }^{35}$ Conversely, alcohol increases the urinary excretion of magnesium and calcium. ${ }^{49,50,52}$ It is possible that magnesium and calcium are depleted in habitual drinkers, and the alcohol-induced changes in these minerals may contribute to BP elevation and arrhythmia. ${ }^{3,53}$

\section{ALCOHOL AND HYPERTENSION}

\section{Epidemiological studies}

Numerous epidemiological observational studies have examined the relationship between alcohol consumption and BP or hypertension. Almost all of them have shown that habitual drinkers have a higher BP 


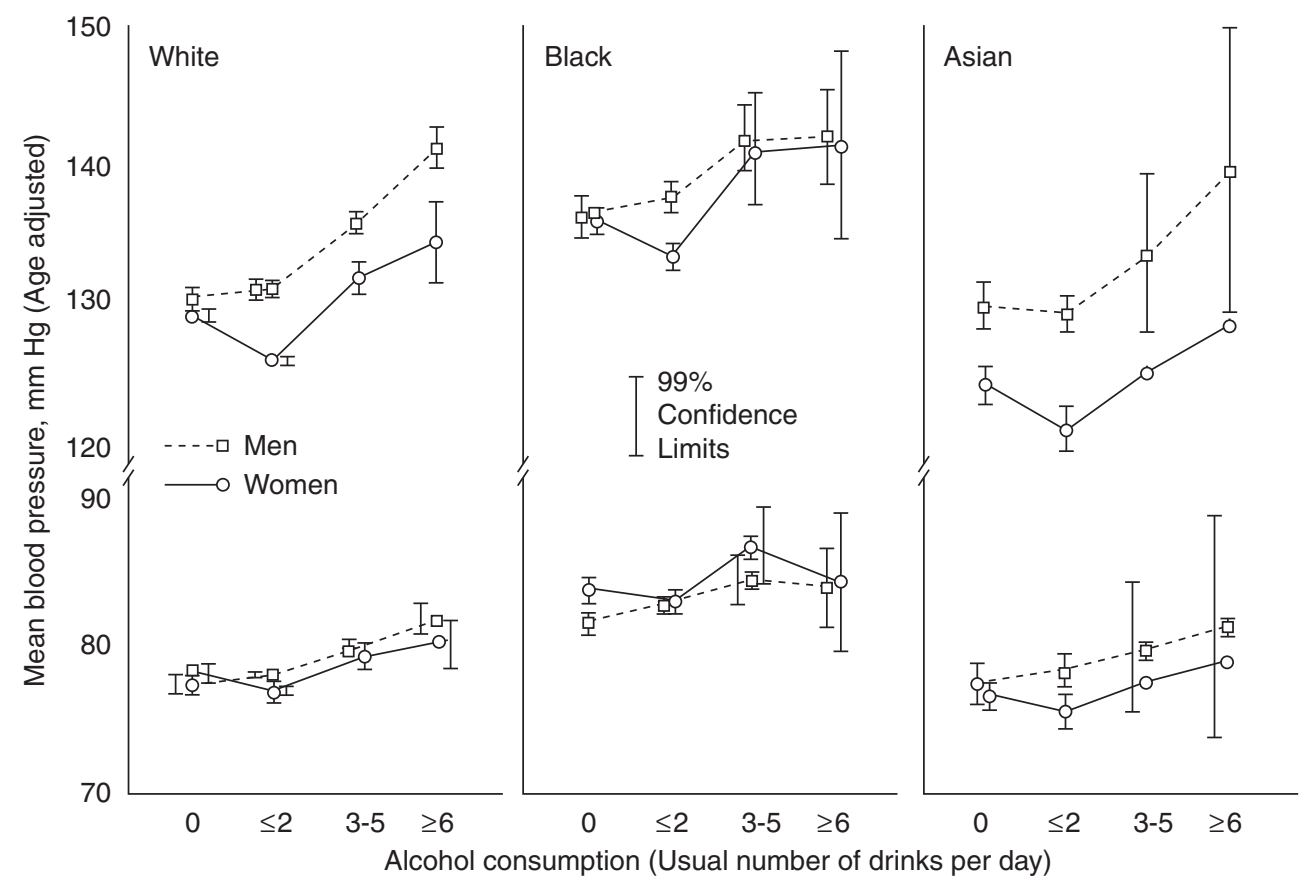

Figure 2 Mean systolic and diastolic BPs for White, Black or Asian men and women for known drinking habits (adopted from Klatsky et al. ${ }^{54}$ with permission).

and higher prevalence of hypertension than nondrinkers. ${ }^{1-3,54-58}$ These associations have been observed regardless of race, gender, age and the type of alcohol (Figure 2). Although some studies suggest the presence of a threshold regarding the pressor effect of alcohol, ${ }^{59,60}$ the relationship between the level of alcohol consumption and BP is usually linear. In cross-sectional studies, the systolic BP increased by 3-4 $\mathrm{mm} \mathrm{Hg}$ and diastolic BP increased by $1-2 \mathrm{~mm} \mathrm{Hg}$ per three drinks per day (one drink contained $10-15 \mathrm{ml}$, or $8-12 \mathrm{~g}$ of alcohol). ${ }^{1}$ Intake of $10 \mathrm{ml}$ per day of alcohol therefore seems to elevate the systolic BP by about $1 \mathrm{~mm} \mathrm{Hg}$ in humans. It has been estimated that about $10 \%$ of hypertension in the general population can be attributed to alcohol. ${ }^{1-3}$

The relationship between alcohol and BP seems to be independent of confounding variables. Increases in the body weight and abdominal fat associated with alcohol consumption, however, may have a role in alcohol-related hypertension. Suter et al. ${ }^{61}$ observed that both the BP and waist/hip ratio increased with the level of alcohol intake, and there was a positive association between changes in body weight and alcohol consumption.

The hypertensive effect of alcohol has also been shown in longitudinal studies. ${ }^{62-64}$ Tsuruta et al. ${ }^{62}$ reported that the probability of the development of hypertension in heavy drinkers (alcohol consumption $\geqq 46$ g per day) was about twice that of the rest of the population after a 12-year follow-up among normotensive men. Fuchs et al. ${ }^{63}$ showed that the consumption of alcohol at $\geqq 30 \mathrm{~g}$ per day was an independent risk factor among participants in the Atherosclerosis Risk in Communities (ARIC) study. Nakanishi et al. ${ }^{64}$ also observed that the risk for hypertension increased in a dose-dependent manner with increases in alcohol intake among Japanese men in a longitudinal study.

Although epidemiological studies have clearly shown the hypertensive effect of alcohol, most studies did not consider the time-related effect of alcohol on BP. This fact may be important because BP measurement has been carried out during the daytime, whereas alcohol is usually consumed at night. Moreira et al. ${ }^{65}$ reported that the BP in habitual drinkers was higher at 13-24 h after the last drink compared with that within $3 \mathrm{~h}$ or at more than $24 \mathrm{~h}$. Kawabe et al. ${ }^{66}$ observed that the evening home BP was lower but the morning home BP was higher on drinking compared with nondrinking days in Japanese volunteers. These findings suggest that the BP in habitual drinkers is overestimated by casual BP measurement taken during the day.

\section{Clinical studies}

Clinical intervention studies have also revealed an increase in BP with alcohol consumption and a BP decrease with alcohol restriction. Howes and Reid, ${ }^{67}$ observed a BP increase after repeated alcohol consumption for 7 days in normotensive subjects. Potter and Beevers ${ }^{68}$ reported a BP increase after alcohol intake for 4 days in hypertensive patients. Using a crossover design, Puddey et al. ${ }^{69,70}$ compared BP values during a 6-week period of unrestricted alcohol consumption and that of alcohol restriction in normotensive and hypertensive subjects. The average level of alcohol consumption was $50 \mathrm{ml}$ per day during the unrestricted period and $10 \mathrm{ml}$ per day during the restricted period, and the $\mathrm{BP}$ was $3 / 2 \mathrm{~mm} \mathrm{Hg}$ higher in the former than in the latter period in normotensive subjects. ${ }^{69}$ In hypertensive subjects, the BP was $5 / 3 \mathrm{~mm} \mathrm{Hg}$ higher in the unrestricted than during the restricted period. ${ }^{70}$ Ueshima et al. ${ }^{71}$ also examined the effect of a 2-week period of alcohol intake and restriction using a crossover method in Japanese hypertensive patients and observed a similar BP elevation with alcohol consumption.

According to a meta-analysis of 15 randomized controlled trials, $\mathrm{BP}$ significantly decreased with alcohol restriction ${ }^{72}$ (Figure 3 ). The mean $\mathrm{BP}$ reduction was $3.3 / 2.0 \mathrm{~mm} \mathrm{Hg}$, and there was a dose-response relationship between alcohol reduction and decrease in BP. The effects of intervention were enhanced in studies with a higher baseline BP. The results of this meta-analysis support the importance of alcohol reduction in the management of hypertension among heavy drinkers.

Most clinical studies have not considered the timing of alcohol intake and BP measurement. We studied the effect of repeated episodes of alcohol consumption on BP with ABPM under standar- 


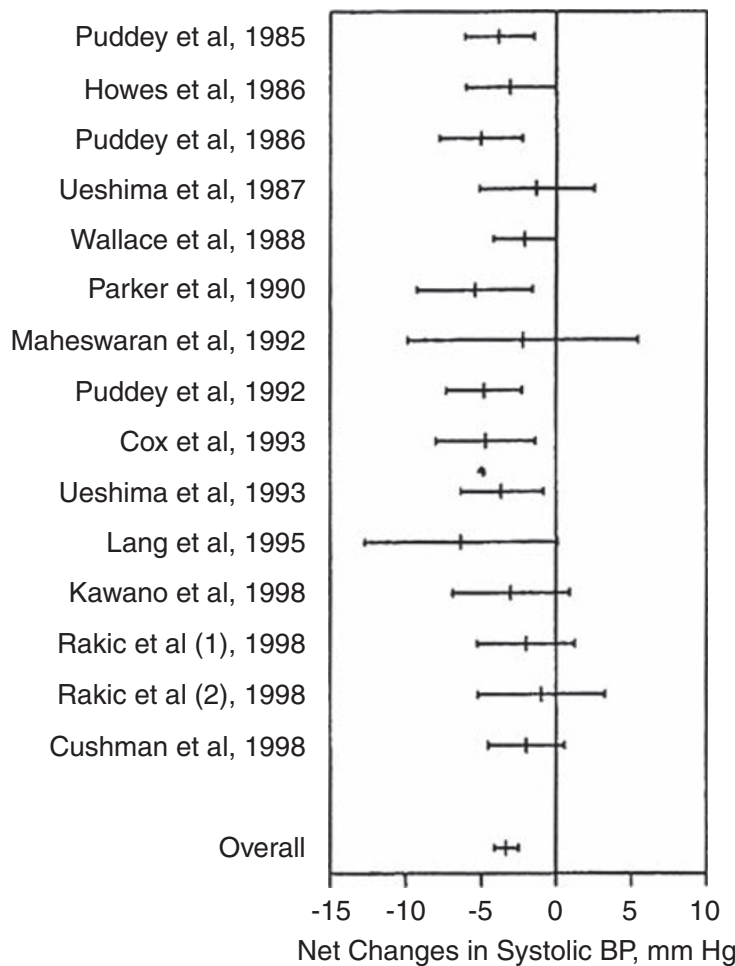

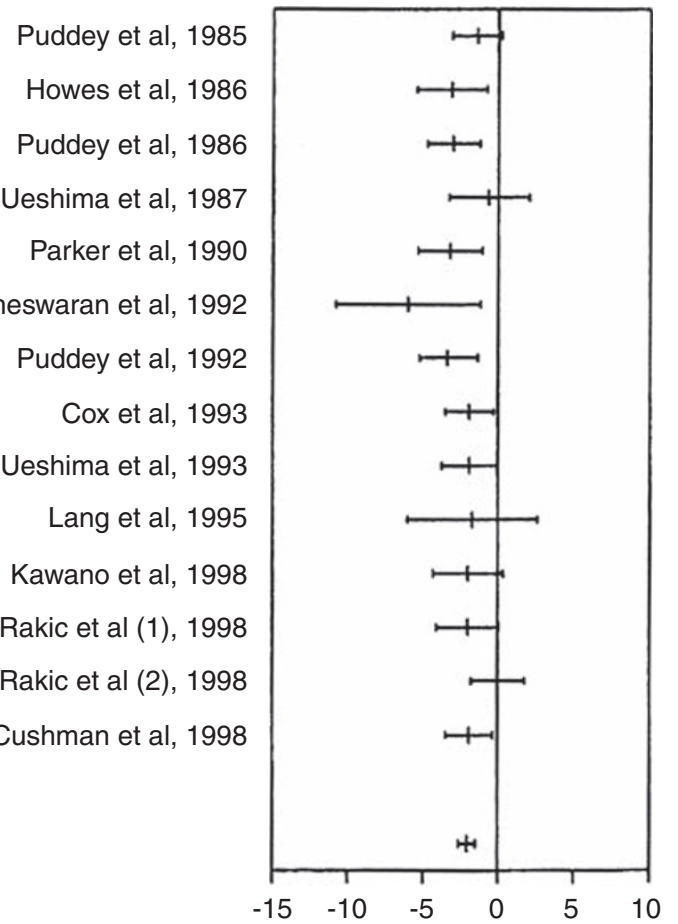

Net Changes in Diastolic BP, $\mathrm{mm} \mathrm{Hg}$

Figure 3 Average net changes in systolic and diastolic BPs and corresponding 95\% Cls related to alcohol reduction intervention in 15 randomized controlled trials (adopted from Xin et al. ${ }^{72}$ with permission).

dized conditions in Japanese men with hypertension. ${ }^{73}$ After several days of the control period, the subjects consumed $1 \mathrm{ml} \mathrm{kg}^{-1}$ of alcohol with an evening meal for 7 days. Evening BP values decreased for several hours after alcohol consumption on both days 1 and 7, whereas morning BP was unchanged on day 1 but increased on day 7 . The average 24-h BP was lower on day 1 and was the same on day 7 compared with the control period. A short-term repeated intake of alcohol therefore causes biphasic changes in BP without altering the average 24-h BP, at least in Japanese men.

We also examined the effect of a 4 -week period of unrestricted alcohol consumption and that of alcohol restriction on the 24-h BP in hypertensive patients in a randomized crossover study. ${ }^{74}$ The average level of daily alcohol intake was $66 \mathrm{ml}$ in the unrestricted period and $11 \mathrm{ml}$ in the restricted period. The daytime BP was $3 / 2 \mathrm{~mm} \mathrm{Hg}$ higher in the unrestricted period than in the restricted period, but the nighttime BP was $4 / 2 \mathrm{~mm} \mathrm{Hg}$ lower in the former (Figure 4). The average 24-h BP was comparable between the two periods. These effects of alcohol resulted in changes in the dipping pattern of the 24-h BP. Half of those who did not show a dip in BP during the restricted period changed and showed a dip in the unrestricted period, and half of those that showed a dip showed an extreme dip during this period.

On the other hand, Minami et al. ${ }^{75}$ observed reductions in the daytime $(-3.4 \mathrm{~mm} \mathrm{Hg})$ and $24-\mathrm{h}(-3.2 \mathrm{~mm} \mathrm{Hg})$ systolic BPs after 3 weeks of alcohol restriction in Japanese men. In their study, daytime, nighttime and 24-h diastolic BPs did not change with alcohol reduction $(-1.1,+2.1$ and $-0.3 \mathrm{~mm} \mathrm{Hg}$, respectively).

The effect of alcohol on the 24-h BP may differ between Orientals and Caucasians. Howes et al. ${ }^{76}$ observed that short-term alcohol intake increased BP variability without changing the average BP in Australian subjects. However, Rakic et al. ${ }^{77}$ showed that the average 24-h BP increased significantly after 4 weeks of alcohol consumption in Australian men. In their study, the average 24-h systolic BP was 2-3 mm Hg higher and the nighttime BP was not lower in the unrestricted compared with the restricted period. It was also reported that the average 24-h BP decreased after abstinence in alcoholic patients. ${ }^{78}$

In a systematic review, McFadden et al. ${ }^{79}$ analyzed clinical trials that examined the BP after a period of sustained alcohol intake. In this review, the pressor effect of alcohol was evident in non-ABPM studies, but not in ABPM studies. An early effect of reducing the BP and a later effect of raising the BP led to smaller differences in the net effect of alcohol on BP values in ABPM studies.

We also studied changes in morning and evening home BP measurements during each of the 4 weeks of unrestricted consumption and restriction in hypertensive patients. ${ }^{80}$ In this study, the morning BP increased by $4.4 \mathrm{~mm} \mathrm{Hg}$ but late evening BP decreased by $7.4 \mathrm{~mm} \mathrm{Hg}$ at the end of the unrestricted alcohol intake period. The pressor effect was significant from week 2, whereas the depressor effect was evident from day 1 . These results indicate that the status of alcohol intake influences the morning-evening BP difference, and that slow pressor mechanism(s) are involved in alcohol-induced BP elevation.

It is therefore clear that alcohol consumption contributes to hypertension, and alcohol restriction decreases the daytime BP. It should be noted, however, that the effects of alcohol on BP vary according to the level and duration of consumption and the time from the last drink. Alcohol seems to exert a marked influence on circadian $\mathrm{BP}$ variation, whereas its influence on the average 24-h BP seems to be small. The mechanisms of the pressor effects of alcohol have not been fully clarified; however, changes in vascular reactivity and sympathetic nerve activity related to intermittent alcohol withdrawal seem to be more important than the direct actions of alcohol. Deficiencies in 

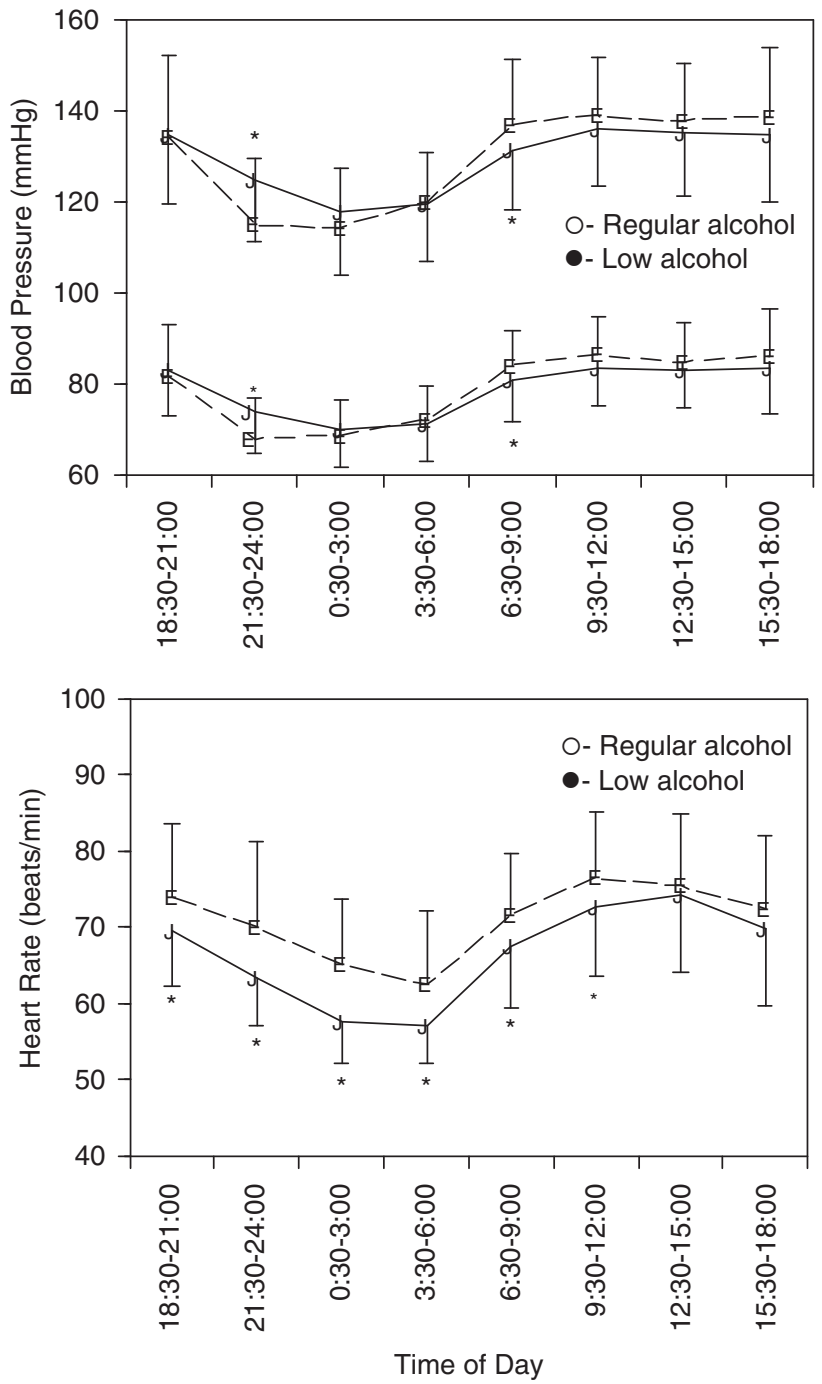

Figure 4 Profile of 24-h BP and heart rate at the end of the regular-alcohol period and the low-alcohol period in hypertensive patients. ${ }^{*} P<0.05$ between the two periods (adopted from Kawano et al. ${ }^{74}$ with permission).

magnesium and calcium may contribute to BP elevation after chronic alcohol consumption. Increases in the caloric intake through consuming alcoholic beverages and elevated salt intake associated with drinking may also be involved in alcohol-related hypertension.

\section{Experimental studies}

Many experimental studies have examined the effect of chronic administration of alcohol on BP; however, the results have been inconsistent.

Strickland and Wooles, ${ }^{81}$ reported an elevation of BP after ethanol administration (5-20\% in drinking water) for 4 weeks in rats. In their study, the plasma level of norepinephrine was decreased in ethanol-fed animals. Vasdev et al. ${ }^{82}$ observed BP elevation after 1 week during the administration of ethanol (5-10\%) to Wister Kyoto rats. They noted increases in the concentration of platelet intracellular calcium ions and the uptake of calcium in the aorta. Hsieh et al. ${ }^{53}$ identified increases in BP and intracellular calcium ions and a decrease in intracellular magnesium ions after 4 weeks of ethanol administration (15\%) to rats. They suggested a role of magnesium deficiency in ethanol- induced hypertension as the BP elevation was attenuated by magnesium supplementation. Puddey et al. ${ }^{83}$ reported a BP elevation of $\sim 10 \mathrm{~mm} \mathrm{Hg}$ and decreases in the level of phospholipids and the ratio of unsaturated/saturated fatty acids in the aorta and kidney after the chronic administration of alcohol to rats. Harada et al. ${ }^{84}$ also observed increases in the BP and platelet-free calcium concentration with ethanol consumption (15\%) in Wister Kyoto rats.

In some studies, the BP did not change after the chronic administration of alcohol to animals. Abdel-Rahman ${ }^{85}$ reported that the BP increase was not different between ethanol-fed (5-20\% in drinking water) spontaneously hypertensive $(\mathrm{SH})$ rats and control $\mathrm{SH}$ rats during a 13-week observation period. The depressor effect of clonidine, however, was reduced in the ethanol-fed $\mathrm{SH}$ rats, suggesting a change in the neural regulation of $\mathrm{BP}$.

Several studies have shown that chronic alcohol intake decreases BP in animals. Howe et al. ${ }^{86}$ reported that BP values in alcohol-fed (5$20 \%$ in drinking water) Wister Kyoto, $\mathrm{SH}$ and stroke-prone $\mathrm{SH}$ rats were lower than those of respective control rats during a 6-month observation period. Hatton et al. ${ }^{87}$ observed a BP decrease during chronic ethanol administration (36\% in a liquid diet) for 18 weeks in Wistar rats. The vasoconstrictor response of resistant arteries to norepinephrine was enhanced and the vasodilator response to alcohol was attenuated in their study. Beilin et al. ${ }^{88}$ reported a decrease in the resting BP of Wister Kyoto and $\mathrm{SH}$ rats after 12 weeks of ethanol administration (20\% in drinking water), although cardiovascular reactivity to noise-related stress was augmented in the ethanol-fed SH rats. El-Mas and Abdel-Rahman ${ }^{89}$ also observed a lower BP in freely moving, ethanol-fed ( $5 \%$ in a liquid diet) rats compared with control rats based on telemonitoring of the BP.

The reasons for the inconsistent results in experimental studies are not clear, but cannot be explained by differences in daily doses of alcohol administration. The periods of alcohol administration, however, are generally longer in studies showing BP reduction than those showing BP elevation. The timing of BP measurement may be important, such as in clinical studies. Crandall et al. ${ }^{90}$ administered $30 \%$ alcohol twice daily $\left(7-8 \mathrm{~g} \mathrm{~kg}^{-1}\right)$ for 10 weeks to rats and examined the levels of BP and blood alcohol. In their study, BP was normal at the time of the peak blood alcohol level but was elevated at $24 \mathrm{~h}$ after alcohol consumption, when alcohol was not detected in the plasma. Their results suggest that alcohol-induced hypertension is not because of its direct action but to alcohol withdrawal.

The harmful effects of large doses of alcohol, such as cardiac dysfunction, have been shown in experimental studies. ${ }^{91}$ Schlicht et al..$^{92}$ however, reported that the lifespan of $\mathrm{SH}$ rats was prolonged by the chronic administration of ethanol. These observations are important, as both the adverse effects of a large amount of alcohol and the beneficial effects of a moderate amount on cardiovascular disease and total mortality have been shown in large-scale epidemiological studies. ${ }^{8-12}$

\section{Interaction with antihypertensive drugs}

Alcohol interacts with several antihypertensive agents. Experimental studies have shown that alcohol attenuates the effect of centrally acting antihypertensive drugs such as clonidine. ${ }^{86}$ Heavy drinking is recognized as one of the factors responsible for resistant hypertension. The interaction between alcohol and antihypertensive drugs and the hypertensive effect of alcohol may have a role in alcohol-related resistant hypertension. In addition, heavy drinkers often show poor adherence to both pharmacological treatment and lifestyle modifications. Habitual drinkers taking antihypertensive drugs are also prone to morning hypertension. ${ }^{93}$ 
Table 2 Moderation of alcohol consumption recommended by hypertension treatment guidelines

\begin{tabular}{lll}
\hline JNC-7 (2003) & ESH-ESC 2007 & JSH 2009 \\
\hline Men: $\leqq 2$ drinks per day & Men: $\leqq 20-30 \mathrm{~g}$ & Men: $\leqq 20-30 \mathrm{ml}$ \\
$(\leqq 30 \mathrm{ml}$ per day) & per day & per day \\
Women, light weight person: & Women: $\leqq 10-20 \mathrm{~g}$ & Women: $\leqq 10-20 \mathrm{ml}$ \\
$\leqq 1$ drink per day ( $\leqq 15 \mathrm{ml}$ per day) & per day & per day \\
\hline
\end{tabular}

Expressed as amount of ethanol. ESH-ESC 2007, European Society of Hypertension-European Society of Cardiology guidelines; ${ }^{5}$ JNC-7, Joint National Committee 7th report (Chobanian et al. ${ }^{4}$ ); JSH 2009, Japanese Society of Hypertension guidelines (Ogihara et al. ${ }^{6}$ ).

The combination of alcohol and antihypertensive drugs may also lead to a marked BP reduction. This phenomenon has been known; however, few clinical studies have addressed this interaction. It is possible that sympatholytic drugs augment the depressor effect of alcohol, as alcohol-induced hypotension is associated with the reflex activation of the sympathetic nervous system. ${ }^{7}$ In our studies, alcohol and a beta blocker, propranolol, additively lowered the nighttime $\mathrm{BP}^{35}$ whereas alcohol and an alpha blocker, prazosin, synergistically acted to lower the BP in hypertensive patients. ${ }^{94}$ It has also been reported that alcohol enhances the depressor effect of the calcium antagonist felodipine. ${ }^{95}$ Changes in the type and timing of antihypertensive medication along with the moderation of alcohol consumption should be considered to treat hypertensive patients with a drinking habit.

\section{Hypertension treatment guidelines}

As an excess consumption of alcohol is a risk factor for hypertension, all hypertension treatment guidelines recommend the moderation of alcohol intake as a part of lifestyle modifications for the management of hypertension (Table 2). The 7th report of the Joint National Committee in the United States (JNC-7) recommends the limitation of daily alcohol consumption to no more than two drinks $(30 \mathrm{ml})$ for most men and to no more than one drink $(15 \mathrm{ml})$ for women and light-weight men. ${ }^{4}$ According to the European guidelines (European Society of Hypertension-European Society of Cardiology guidelines, ESH-ESC 2007), the upper limit is $20-30 \mathrm{~g}$ per day for men and 10-20 g per day for women. The Japanese guidelines provide similar recommendations (20-30 ml per day for men and $10-20 \mathrm{ml}$ per day for women). Of note, $600 \mathrm{ml}$ of beer or $250 \mathrm{ml}$ of wine contains about $30 \mathrm{ml}$ of ethanol.

These recommendations put forward by the guidelines are appropriate because small doses of alcohol exert little adverse effects on BP and the cardiovascular system. There are, however, some concerns regarding the efficacy of alcohol restriction on BP because the effect of alcohol on average 24-h BP levels seems to be very small. In our studies, salt restriction and weight reduction substantially decreased the BP for $24 \mathrm{~h}$, but the effect of alcohol restriction on average 24-h BP was not significant. ${ }^{96-98}$ As light drinking has beneficial effects on the cardiovascular system, as described later, abstinence from alcohol should not be imposed on hypertensive individuals except for patients with special conditions.

\section{ALCOHOL AND CARDIOVASCULAR DISEASE}

\section{Cardiac disease}

Heart failure. A heavy alcohol intake is associated with cardiac hypertrophy and the risk of cardiomyopathy and heart failure. , $^{8,36,37}$ It has been shown that the total consumption of alcohol is positively related to a left ventricular mass and is negatively associated with the ejection fraction in asymptomatic alcoholic subjects. ${ }^{37}$ Recent epide-

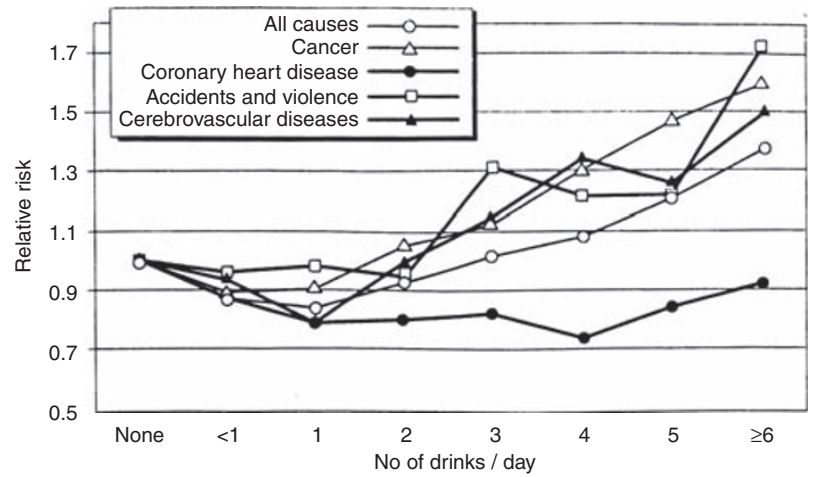

Figure 5 Alcohol consumption and relative risk of death over 12 years in American Cancer Society prospective study of 276802 men aged 40-59 (adopted from Boffetta et al. ${ }^{105}$ with permission).

miological studies, however, have shown that moderate alcohol consumption is associated with a lower risk of heart failure. ${ }^{99,100}$ Klatsky et al. ${ }^{101}$ reported that heavy drinkers had an increased risk of heart failure because of noncoronary artery disease, whereas alcohol drinking was inversely related to the risk of heart failure because of coronary artery disease. Heavy drinking therefore seems to increase the risk of heart failure but light-to-moderate drinking may decrease the risk, probably because of its favorable association with coronary artery disease.

Arrhythmia. Alcohol intake is associated with the risk of tachyarrhythmia, such as ventricular and supraventricular premature contractions and atrial fibrillation. ${ }^{8,102-104}$ In the Danish Diet, Cancer and Health study, moderate-to-heavy consumption of alcohol was associated with an increased risk of atrial fibrillation. ${ }^{103,104}$ Such alcoholinduced arrhythmia often occurs after binge drinking. Activation of the sympathetic nervous system and a decrease in the serum potassium level after drinking may trigger this arrhythmia. ${ }^{3}$ Cardiac functional and structural changes because of chronic alcohol consumption also seem to have a role in arrhythmia. ${ }^{37}$

Coronary heart disease. Alcohol seems to have a beneficial effect on coronary heart disease. ${ }^{8,9}$ It has been shown that the risk of myocardial infarction is $20-50 \%$ lower in habitual compared with nondrinkers. ${ }^{9,105-108}$ This risk reduction is dose-dependent up to the level of moderate drinking, but further risk reduction has not been observed in heavy drinkers (Figure 5). A U-shaped relationship has been observed between the level of alcohol consumption and degree of coronary calcification in a general population. ${ }^{109}$ In some studies, such as the Japan Collaborative Cohort Study, ${ }^{110}$ the beneficial effect of alcohol on coronary heart disease was modest and not significant (Table 3).

The mechanisms behind the inverse association of alcohol with coronary heart disease have not been fully clarified. The alcoholinduced increase in HDL cholesterol, however, seems to be the most important mechanism. ${ }^{107,111}$ The inhibitory effect of alcohol on blood coagulation also contributes to the lower risk of myocardial infarction. ${ }^{107}$ In addition, it has been shown that moderate alcohol consumption is associated with a lower plasma level of C-reactive protein, suggesting an anti-inflammatory action of alcohol. ${ }^{112}$ The weak effect of alcohol on the average 24-h BP may also have a role as a high BP is a strong risk factor for coronary heart disease. ${ }^{74,79}$

Red wine contains polyphenols that act to prevent atherosclerosis because of their antioxidant effect. Several studies have shown that 
Table 3 Mortality from stroke, coronary heart disease and total cardiovascular disease by alcohol consumption category in men in the Japan Collaborative Cohort Study (adopted from Ikehara et al. ${ }^{110}$ with modification)

\begin{tabular}{|c|c|c|c|c|c|c|}
\hline & Nondrinkers & Ex-drinkers & $0.1-22.9$ & $23.0-45.9$ & $46.0-68.9$ & $\geqq 69.0$ \\
\hline Total stroke & 200 & 126 & 114 & 168 & 173 & 83 \\
\hline Age-adjusted HR & 1.00 & $1.93^{\mathrm{a}}$ & 0.91 & 0.98 & $1.46^{\mathrm{a}}$ & $1.89^{\mathrm{a}}$ \\
\hline Hemorrhagic stroke & 55 & 31 & 41 & 52 & 60 & 37 \\
\hline Age-adjusted HR & 1.00 & $1.80^{\mathrm{a}}$ & 1.09 & 1.02 & $1.51^{\mathrm{a}}$ & $2.30^{\mathrm{a}}$ \\
\hline Multivariable $\mathrm{HR}$ & 1.00 & $1.79^{a}$ & 1.16 & 1.02 & 1.47 & $2.16^{a}$ \\
\hline Ischemic stroke & 126 & 88 & 60 & 101 & 95 & 37 \\
\hline Age-adjusted HR & 1.00 & $2.12^{\mathrm{a}}$ & 0.80 & 0.99 & $1.44^{\mathrm{a}}$ & $1.60^{\mathrm{a}}$ \\
\hline Age-adjusted HR & 1.00 & $1.50^{\mathrm{a}}$ & 0.94 & 88 & 0.87 & 1.16 \\
\hline Multivariable $\mathrm{HR}$ & 1.00 & 1.35 & 0.96 & 0.82 & 0.76 & 0.95 \\
\hline Total cardiovascular disease & 487 & 282 & 269 & 379 & 342 & 162 \\
\hline Age-adjusted HR & 1.00 & $1.77^{a}$ & 0.88 & 0.90 & $1.16^{\mathrm{a}}$ & $1.47^{\mathrm{a}}$ \\
\hline Multivariable HR & 1.00 & $1.66^{\mathrm{a}}$ & 0.90 & 0.87 & 1.07 & $1.28^{\mathrm{a}}$ \\
\hline
\end{tabular}

Abbreviation: HR, hazard ratio.

asignificant $v s$. nondrinkers.

people who mainly drink red wine have a lower risk of cardiovascular disease than those who drink other kinds of alcoholic beverage. ${ }^{113,114}$ It is suggested, however, that the low incidence of myocardial infarction in habitual drinkers is largely attributed to the effect of alcohol itself. $^{115}$

\section{Cerebrovascular disease}

The relationship between alcohol consumption and total cerebrovascular disease is generally J-shaped, although it differs according to subtypes of stroke ${ }^{105,116}$ (Figure 5). It is clear that alcohol is a risk factor for hemorrhagic stroke. A positive linear relationship has been observed between the level of alcohol consumption and risk of brain or subarachnoid hemorrhage. . $^{8110,116,117}$ Actions on the BP and blood coagulation system seem to be underlying mechanisms for this adverse influence of alcohol.

On the other hand, the relationship between alcohol consumption and the risk of ischemic stroke has been found to be J- or Ushaped. ${ }^{110,116-118}$ The low risk in light drinkers seems to be due to the lower degree of atherosclerosis and the inhibition of blood coagulation, as in the case of ischemic heart disease. The increased risk in heavy drinkers is probably related to increases in the level and variability of the BP, hemoconcentration because of dehydration and thromboembolism associated with alcohol-induced atrial fibrillation. Regarding alcoholic beverage types, wine drinkers seem to have a lower risk of ischemic stroke. ${ }^{119,120}$

The favorable association of light-to-moderate drinking with the risk of ischemic stroke seems to be more apparent in Caucasians than in Japanese, although the results of epidemiological studies have been inconsistent in both populations. The racial differences may be related to variation in the frequencies of stroke subtypes. Atherothrombotic brain infarction is common in Caucasians, whereas lacunar stroke is more common in Japanese.
Several studies have examined the relationship between alcohol intake and subclinical findings on magnetic resonance imaging of the brain in general populations. In the Cardiovascular Study, a U-shaped relationship was observed between alcohol consumption and white matter abnormalities. Moreover, moderate drinking was also associated with a lower risk of lacunar infarction compared with abstainers. ${ }^{121}$ Such risk reduction with moderate drinking, however, was not observed in the ARIC study, and an increased level of alcohol intake was associated with brain atrophy. ${ }^{122}$

\section{Peripheral arterial disease and atherosclerosis}

As light-to-moderate consumption of alcohol seems to act to suppress the progression of atherosclerosis, it may also have a favorable influence on peripheral arterial disease. The Edinburgh Artery Study supported the protective effect of alcohol, as there was a positive association between the level of alcohol intake and the ankle brachial index. ${ }^{123}$ In the Physicians' Health Study, habitual drinkers showed a $26 \%$ lower incidence of peripheral arterial disease compared with nondrinkers after adjustment for confounding factors. ${ }^{124}$ Similar results were also shown in the Framingham Heart Study and the ARIC study. ${ }^{125,126}$

Regarding the association of alcohol and carotid atherosclerosis, an inverse relationship was noted in the Lausanne Stroke Registry. ${ }^{127} \mathrm{On}$ the other hand, there was no significant association between alcohol intake and the carotid artery thickness in the ARIC study. ${ }^{128} \mathrm{~A} \mathrm{U}$ - or J-shaped relationship was observed between the level of alcohol intake and severity of carotid atherosclerosis in the Bruneck Study and the Study of Health in Pomerania. ${ }^{129,130}$ Although the results of epidemiological studies have been inconsistent, light-to-moderate consumption seems to inhibit the development of carotid atherosclerosis.

Several studies examined the relationship between alcohol consumption and arterial stiffness by measuring the pulse wave velocity. 
Sierksma et al. ${ }^{131}$ identified a U-shaped relationship between alcohol consumption and the aortic pulse wave velocity. van den Elzen et al. ${ }^{132}$ observed an inverse relationship between the alcohol intake and pulse wave velocity in young men and women. On the other hand, Kurihara et al. ${ }^{133}$ reported that the brachial-ankle pulse wave velocity was elevated in heavy drinkers. These studies also support the favorable effect of moderate and the harmful effect of heavy drinking on large arteries.

\section{Cardiovascular mortality and total mortality}

As described earlier, alcohol seems to exert both beneficial and adverse effects on cardiovascular diseases. The relationship between alcohol consumption and total cardiovascular mortality has been shown to be J-, U- or L-shaped. A J-shaped relationship was observed in the Japan Collaborative Cohort Study; however, the beneficial effect of light-tomoderate drinking was not significant. ${ }^{110}$ On the other hand, in very large longitudinal studies conducted by the American Cancer Society, a U-shaped relationship was observed in the original study, ${ }^{105}$ and the relationship was L-shape (nondrinkers showed the highest cardiovascular mortality) in Study II. ${ }^{10}$ In a meta-analysis conducted by Di Castelnuovo et al., ${ }^{114}$ a light-to-moderate consumption of wine or beer was associated with lower cardiovascular risk. A drinking habit, particularly wine consumption, has been shown as a part of a lifestyle associated with low cardiovascular risk. ${ }^{134,135}$ It has also been suggested that the risk reduction associated with alcohol consumption is low in individuals without cardiovascular risk factors but is high in those with a marked cardiovascular risk. Taken together, light-tomoderate alcohol consumption seems to decrease cardiovascular mortality, whereas heavy drinking may result in poor cardiovascular outcomes compared with abstainers.

Alcohol is also related to several cancers, liver disease, psychiatric and neurological disorders and injury, and it seems to influence total mortality. A J- or U-shaped relationship has been observed between the level of alcohol intake and total mortality. ${ }^{10,11,105,136,137}$ It has been suggested that all-cause mortality is the lowest among subjects who consume about one drink per day. In the American Cancer Society Prospective Study II, total mortality was lower in drinkers than in nondrinkers. ${ }^{10}$ It has also been shown that wine drinkers have a lower mortality rate than drinkers who avoid wine. ${ }^{136}$ In a meta-analysis of 34 studies including more than one million individuals, a J-shaped relationship was found between alcohol consumption and total mortality. ${ }^{11}$ In this analysis, low levels of alcohol intake (one to two drinks per day for women and two to four drinks per day for men) were inversely associated with total mortality, although higher levels of alcohol increased mortality. Those findings suggest that a lightto-moderate intake of alcohol decreases but heavy consumption increases total mortality compared to nondrinking.

\section{CONCLUSIONS}

Alcohol has complex effects on the cardiovascular system. It is clear that alcohol consumption is related to hypertension, and therefore the restriction of alcohol intake is recommended in the management of hypertension. Alcohol and its metabolites, however, also exhibit a vasodilatory action, and the BP usually decreased after alcohol ingestion, especially in Orientals who show alcohol flush. Mechanisms for the pressor action of alcohol have not been completely clarified; however, an increase in the vascular sensitivity, activation of the sympathetic nervous system and depletion of magnesium and calcium may be involved. The depressor action of alcohol is due to a decrease in systemic vascular resistance that may be related to the attenuation of vascular sensitivity and production of nitric oxide. The pressor effect of alcohol consumed in the evening is apparent during the day, but its effect on average 24-h BP seems to be very small. It should be mentioned that casual BP measurement may lead to overestimating the hypertensive effect of alcohol.

Alcohol seems to exert both harmful and beneficial effects on cardiovascular disease. An excessive intake of alcohol is associated with increased risks of heart failure, arrhythmia and hemorrhagic stroke and causes an increase in total mortality. Light-to-moderate drinkers, however, show lower rates of atherosclerosis and lower risks of coronary heart disease, heart failure, ischemic stroke, peripheral artery disease and cardiovascular and total mortality compared with nondrinkers. As the aim of the management of hypertension is the prevention of cardiovascular disease and premature death, moderation of alcohol intake is to be recommended to hypertensive patients, but abstinence from alcohol should not be insisted on unless there are specific indications for it.

1 McMahon S. Alcohol consumption and hypertension. Hypertension 1987; 9: 111-121.

2 Beilin LJ, Puddey IB. Alcohol and hypertension: an update. Hypertension 2006; 47: 1035-1038.

3 Kawano Y. Alcohol and hypertension: state of the art. Clin Hypertens 2000; 6: 14-28.

4 Chobanian AV, Bakris GL, Black HR, Cushman WC, Green LA, Izzo Jr JL, Jones DW, Materson BJ, Oparil S, Wright Jr JT, Roccela ET. the National High Blood Pressure Education Program Coordinating Committee: the seventh report of the Joint National Committee on Prevention, Detection, Evaluation, and Treatment of High Blood Pressure. Hypertension 2003; 42: 1206-1252.

5 The task force for the management of arterial hypertension of the European Society of Hypertension (ESH) and of the European Society of Cardiology (ESC): 2007 guidelines for the management of arterial hypertension. J Hypertens 2007; 25: 1105-1187.

6 Ogihara T, Kikuchi K, Matsuoka H, Fujita T, Higaki J, Horiuchi M, Imai Y, Imaizumi T, Ito S, Iwao H, Kario K, Kawano Y, Kim-Mitsuyama S, Kimura G, Matsubara H, Matsuura H, Naruse M, Saito I, Shimada K, Shimamoto K, Suzuki H, Takishita S, Tanahashi N, Tsuchihashi T, Uchiyama M, Ueda S, Ueshima H, Umemura S, Ishimitsu $\mathrm{T}$, Rakugi $\mathrm{H}$. The Japanese Society of Hypertension guidelines for the management of hypertension (JSH 2009). Hypertens Res 2009; 32: 3-107.

7 Kawano Y, Abe H, Kojima S, Ashida T, Yoshida K, Imanishi M, Yoshimi H, Kimura G, Kuramochi M, Omae T. Acute depressor effect of alcohol in patients with essential hypertension. Hypertension 1992; 20: 219-226.

8 Regan JT. Alcohol and the cardiovascular system. JAMA 1990; 264: 377-381.

9 Marmot M, Brunner E. Alcohol and cardiovascular disease: the status of the $\mathrm{U}$ shaped curve. Br Med J 1991; 303: 565-568.

10 Thun MG, Peto R, Lopez AD, Monaco JH, Henley SJ, Hearth Jr CW, Doll R. Alcohol consumption and mortality among middle-aged and elderly US. Adults. $N$ Engl J Med 1997; 337: 1705-1714.

11 Di Castelnuovo A, Costanzo S, Bagnaldi V, Donati MB, lacoviello L, de Gaetano G. Alcohol dosing and total mortality in men and women: an updated meta-analysis of 34 prospective studies. Arch Intern Med 2006; 166: 2437-2445.

12 O'Keefe JH, Bybee KA, Lavie CJ. Alcohol and cardiovascular health: the razor-sharp double-edged sword. J Am Coll Cardiol 2007; 50: 1009-1014.

13 Ireland MA, Vandongen R, Davidson L, Beilin LJ, Rouse IL. Acute effects of moderate alcohol consumption on blood pressure and plasma catecholamines. Clin Sci 1984; 66: 643-648

14 Grassi GM, Somers VK, Renk WS, Abboud FM, Marl AL. Effects of alcohol intake on blood pressure and sympathetic nerve activity in normotensive humans: a preliminary report. J Hypertens 1989; 7(Suppl 6): S20-S21.

15 Kupari M. Acute cardiovascular effects of alcohol: a controlled non-invasive study. $\mathrm{Br}$ Heart J 1983; 49: 174-182.

16 Puddey IB, Vandongen R, Beilin L, Rouse IL. Alcohol stimulation of renin release in man: its relation to the hemodynamic, electrolyte, and sympatho-adrenal responses to drinking. J Clin Endocrinol Metab 1985; 61: 37-41.

17 Riff DR, Jain AC, Doyle JT. Acute hemodynamic effects of ethanol on normal human volunteers. Am Heart J 1969; 78: 592-597.

18 Child JS, Kovick RB, Levisman JA, Pearce ML. Cardiac effects of acute ethanol ingestion unmasked by autonomic blockade. Circulation 1979; 59: 120-125.

19 Potter JF, MacDonald IA, Beevers DG. Alcohol raises blood pressure in hypertensive patients. J Hypertens 1986; 4: 435-441.

20 Carretta R, Fabris B, Bardelli M, Fischetti F, Muiesan S, Vran F, Bellinin G Campanacci L. Hemodynamic effects of intravenous infusion of alcohol in essential hypertension. J Hypertens 1987; 5(Suppl 5): S505-S507.

21 Stott DJ, Ball SG, Inglis GC, Davies DL, Fraser R, Murray GD, McInnes GT. Effects of a single moderate dose of alcohol on blood pressure, heart rate and associated metabolic and endocrine changes. Clin Sci 1987; 73: 411-416. 
22 Minami J, Todoroki M, Ishimitsu T, Tamamoto H, Abe S, Fukunaga T, Matsuoka H. Effects of alcohol intake on ambulatory blood pressure, heart rate, and heart rate variability in Japanese men with different ALDH2 genotypes. J Hum Hypertens 2002; 16: 345-351.

23 Kupari M, Eriksson CJP, Heikkila J, Ylikahri R. Alcohol and the heart: intense hemodynamic changes associated with alcohol flush in Orientals. Acta Med Scand 1983; 213: 91-98.

24 Kupari M, Lindros K, Hillbom M, Heikkila J, Ylikahri R. Cardiovascular effects of acetaldehyde accumulation after ethanol ingestion: their modification by $\beta$-adrenergic blockade and alcohol dehydrogenase inhibition. Alcohol Clin Exp Res 1983; 7: 283-288.

25 Altura BM, Altura BT. Microvascular and vascular smooth muscle actions of ethanol, acetaldehyde, and acetate. Fed Proc 1982; 41: 2447-2451.

26 Howes LG, Reid JL. The effects of alcohol on local, neural and humoral cardiovascular regulation. Clin Sci 1986; 71: 9-15.

27 Criscione L, Powell JR, Burdett R, Engesser S, Schlager F, Schoepfer A. Alcohol suppresses endothelium-dependent relaxation in rat mesenteric vascular beds. Hypertension 1989; 13: 964-967.

28 Brizzolara AL, Morris DG, Burnstock G. Ethanol affects sympathetic cotransmission and endothelium-dependent relaxation in the rat. Eur J Pharmacol 1994; 254: $175-181$.

29 Oshita M, Takei Y, Kawano S, Yoshihara H, Hijioka T, Fukui H, Goto M, Masuda E, Nishimura Y, Fusamoto H, Kamada T. Roles of endothelin-1 and nitric oxide in the mechanism for ethanol-induced vasoconstriction in rat liver. J Clin Invest 1993; 91: 1337-1342.

30 Soardo G, Donnini D, Varutti R, Moretti M, Milocco C, Basan L, Esposito W, Casaccio D, Stel G, Catena C, Curcio F, Sechi LA. Alcohol-induced endothelial changes are associated with oxidative stress and are rapidly reversed after withdrawal. Alcohol Clin Exp Res 2005; 29: 1889-1898.

31 Zilkens RR, Pich L, Burke V, Beilin LJ, Watts GF, Puddey IB. Effects of alcohol intake on endothelial function in men: a randomized controlled trial. J Hypertens 2003; 21 : 97-103.

32 Puddey IB, Zilkens RR, Croft KD, Beilin LJ. Alcohol and endothelial function: a brief review. Clin Exp Pharmacol Physiol 2001; 28: 1020-1024.

33 Kojima S, Kawano Y, Abe H, Sanai T, Yoshida K, Imanishi M, Ashida T, Kimura G, Yoshimi H, Matsuoka H, Omae T. Acute effects of alcohol ingestion on blood pressure and erythrocyte sodium concentration. J Hypertens 1993; 11: 185-190.

34 Lucas DL, Brown RA, Wassef M, Giles TD. Alcohol and the cardiovascular system: research challenges and opportunities. J Am Coll Cardiol 2005; 45: 1916-1924.

35 Kawano Y, Abe H, Kojima S, Takishita S, Omae T. Effects of propranolol on cardiovascular and neurohumoral actions of alcohol in hypertensive patients. Blood Press 1999; 8: 37-42.

36 Manolio TA, Levy D, Garrison RJ, Castelli WP, Kannel WB. Relation of alcohol intake to left ventricular mass: the Framingham Study. J Am Coll Cardiol 1991; 17: 717-721.

37 Urbano-Marquez A, Estruch R, Navarro-Lopez F, Grau JM, Mont L, Rubin E. The effects of alcoholism on skeletal and cardiac muscle. N Engl J Med 1989; 320: 409-415.

38 Capasso JM, Li P, Guideri G, Malhotra A, Cortese R, Anversa P. Myocardial mechanical, biochemical, and structural alterations induced by chronic ethanol ingestion in rats. Circ Res 1992; 71: 346-356.

39 Bannan LT, Potter JF, Beevers DG, Saunders JB, Waters JRF, Ingram MC. Effect of alcohol withdrawal on blood pressure, plasma renin activity, aldosterone, cortisol and dopamine beta-hydroxylase. Clin Sci 1984; 66: 659-663.

40 Soardo G, Donnini D, Varutti R, Milocco C, Basan L, Esposito W, Casaccio D, Isola M, Soldano F, Sechi LA. Effects of alcohol withdrawal on blood pressure in hypertensive heavy drinkers. J Hypertens 2006; 24: 1493-1498.

41 van de Borne P, Mark AL, Montano N, Mion D, Somers VK. Effects of alcohol on sympathetic activity, hemodynamics, and chemoreflex sensitivity. Hypertension 1997; 29: 1278-1283.

42 Kawano Y, Abe H, Imanishi M, Yoshimi H, Takishita S, Omae T. Pressor and depressor hormones during alcohol-induced blood pressure reduction in hypertensive patients. J Hum Hypertens 1998; 10: 595-599.

43 Abdel-Rahman AA, Dar MS, Wooles WR. Effects of chronic ethanol administration on artrial baroreceptor function and pressor and depressor responsiveness in rats. J Pharmacol Exp Ther 1985; 232: 194-201.

44 Narkiewicz K, Cooley RL, Somers VK. Alcohol potentiates orthostatic hypotension: implications for alcohol-related syncope. Circulation 2000; 101: 398-402.

45 Randin D, Vollenweider P, Tappy L, Jequier E, Nicod P, Scherer U. Suppression of alcohol-induced hypertension by dexamethasone. N Eng/ J Med 1995; 332: 1733-1737.

46 Djousse L, Hunt SC, Eckfeldt JH, Arnett DK, Province MA, WEllison RC. Alcohol consumption and plasma atrial natriuretic peptide (from the HyperGEN study). Am J Cardiol 2006; 98: 628-632.

47 Goude G, Fagerberg B, Hulthe J. Alcohol consumption, the metabolic syndrome and insulin resistance in 58-year-old clinically healthy men (AIR study). Clin Sci 2002; 102: 345-352.

48 Wannamethee SG, Camargo Jr CA, Manson JE, Willett WC, Rimm EB. Alcohol drinking patterns and risk of type 2 diabetes mellitus among younger women. Arch Intern Med 2003; 163: 1329-1336.

49 Rubini ME, Kleeman CR, Lamdin E. Studies on alcohol diuresis. 1. The effect of ethyl alcohol ingestion on water, electrolyte and acid-base metabolism. J Clin Invest 1955; 34: 439-447.
50 Kalbfleisch JM, Lindeman RD, Ginn HE, Smith WO. Effects of ethanol administration on urinary excretion of magnesium and other electrolytes in alcoholic and normal subjects. J Clin Invest 1963; 42: 1471-1475.

51 Kawano Y, Abe H, Kojima S, Takishita S, Matsuoka H. Effects of repeated alcohol intake on blood pressure and sodium balance in Japanese men with hypertension. Hypertens Res 2004; 27: 167-172.

52 Hsieh ST, Saito K, Miyajima T, Lin CM, Yokoyama M. Effects of alcohol moderation on blood pressure and intracellular cations in mild essential hypertension. Am J Hypertens 1995; 8: 696-703.

53 Hsieh ST, Sano H, Saito K, Kubota Y, Yokoyama M. Magnesium supplementation prevents the development of alcohol-induced hypertension. Hypertension 1992; 19: $175-182$.

54 Klatsky AL, Friedman GD, Siegelaub AB, Gerald M. Alcohol consumption and blood pressure: Kaiser-Permanente multiphasic health examination data. $N$ Engl J Med 1977; 296: 1120-1194

55 Marmot MG, Elliott P, Shipley MJ, Dyer AR, Ueshima H, Beevers DG, Stamler R, Kesteloot H, Rose G, Stamler J. Alcohol and blood pressure: the INTERSALT study. Br Med J 1994; 308: 1263-1267.

56 Okamura T, Tanaka T, Yoshita K, Chiba N, Takebayashi T, Kikuchi Y, Tamaki J, Tamura U, Minai J, Kadowaki T, Miura K, Nakagawa H, Tanihara S, Okayama A, Ueshima H. Specific alcoholic beverage and blood pressure in a middle-aged Japanese population: the High-risk and Population Strategy for Occupational Health Promotion (HIPOPOHP) study. J Hum Hypertens 2004; 18: 9-16.

57 Stranges S, Wu T, Dorn JM, Freudenheim JL, Muti P, Farinaro P, Russel M, Nochajski $\mathrm{TH}$, Trevisan M. Relationship of alcohol drinking pattern to risk of hypertension: a population-based study. Hypertension 2004; 44: 813-819.

58 Nakamura K, Okamura T, Hayakawa T, Hozawa A, Kadowaki T, Murakami Y, Kita Y, Okayama A, Ueshima $H$. The proportion of individuals with alcohol-induced hypertension among total hypertensives in a general Japanese population: NIPPON DATA 90. Hypertens Res 2007; 30: 663-668.

59 Panagiotakos DB, Kourlaba G, Zeinbekis A, Toutouzas P, Polychronopoulos E. The $J$-shaped association of alcohol consumption on blood pressure levels in elderly people from Mediterranean Islands (MEDIS epidemiological study). J Hum Hypertens 2007; 21: 585-587.

60 Sesso HD, Cook NR, Buring JE, Manson JE, Gaziano JM. Alcohol consumption and the risk of hypertension in women and men. Hypertension 2008; 51: 1080-1087.

61 Suter PM, Maire R, Vetter V. Is an increased waist:hip ratio the cause of alcoholinduced hypertension? The AIR 94 study. J Hypertens 1995; 13: 1857-1862.

62 Tsuruta M, Adachi H, Hirai Y, Fujiura Y, Imaizumi T. Association between alcohol intake and development of hypertension in Japanese normotensive men: 12-year follow-up study. Am J Hypertens 2000; 13: 482-487.

63 Fuchs FD, Chambless LE, Whelton PK, Nieto J, Heiss G. Alcohol consumption and the incidence of hypertension: the Atherosclerosis Risk in Communities study. Hypertension 2001; 37: 1242-1250.

64 Nakanishi N, Yoshida H, Nakamura K, Suzuki K, Tatara K. Alcohol consumption and the risk for hypertension in middle-aged Japanese men. J Hypertens 2001; 19: 851-855.

65 Moreira MB, Fuchs FB, Moraes RS, Bnedemeier M, Duncan BB. Alcohol intake and blood pressure: the importance of time elapsed since last drink. J Hypertens 1998; 16: $175-180$.

66 Kawabe H, Saito I, Saruta T. Effects of nighttime alcohol intake on evening and next morning blood pressure in Japanese normotensives. Clin Exp Hypertens 2007; 29: 43-49.

67 Howes LG, Reid JL. Changes in blood pressure and autonomic reflexes following regular, moderate alcohol consumption. J Hypertens 1986; 4: 421-425.

68 Potter JT, Beevers DG. Pressor effect of alcohol in hypertension. Lancet 1984; i: 119-122.

69 Puddey IB, Beilin LJ, Vandongen R, Rouse IL, Rogers P. Evidence for a direct effect of alcohol consumption on blood pressure in normotensive men: a randomized controlled trial. Hypertension 1985; 7: 707-713.

70 Puddey IB, Beilin LJ, Vandongen R. Regular alcohol use raises blood pressure in treated hypertensive subjects: a randomized, controlled trial. Lancet 1987; i: 647-651.

71 Ueshima H, Ogihara T, Baba S, Tabuchi Y, Mikawa K, Hashizume K, Mandai T, Ozawa $\mathrm{H}$, Kumahara Y, Asakura S, Hisanari M. The effect of reduced alcohol consumption on blood pressure: a randomized, controlled, single blind study. J Hum Hypertens 1987; 1: $113-119$.

72 Xin X, He J, Frontini MG, Ogden LG, Motsamai OI, Whelton PK. Effects of alcohol reduction on blood pressure: a meta-analysis of randomized controlled trials. Hypertension 2001; 38: 1112-1117.

73 Abe H, Kawano Y, Kojima S, Ashida T, Kuramochi M, Matsuoka H, Omae T. Biphasic effects of alcohol intake on 24-h blood pressure in hypertensive patients. Circulation 1994; 89: 2626-2633.

74 Kawano Y, Abe H, Takishita S, Omae T. Effects of alcohol restriction on 24-h ambulatory blood pressure in Japanese men with hypertension. Am J Med 1998; 105: 307-311.

75 Minami J, Yoshii M, Todoroki M, Nishikimi T, Ishimitsu T, Fukunaga T, Matsuoka H. Effects of alcohol restriction on ambulatory blood pressure, heart rate, and heart rate variability in Japanese men. Am J Hypertens 2002; 15: 125-129.

76 Howes LG, Krum H, Phillips PA. Effects of regular alcohol consumption on $24 \mathrm{~h}$ ambulatory blood pressure recordings. Clin Exp Pharmacol Physiol 1990; 17: 247-250.

77 Rakic V, Puddey IB, Burke V, Dimmitt SB, Beilin LJ. Influence of pattern of alcohol intake on blood pressure in regular drinkers: a controlled trial. $J$ Hypertens 1998; 16: $165-174$ 
78 Aguilera MT, de la Sierra A, Coca A, Estruch R, Fernandez-Sola J, Urbano-Marquez A. Effect of alcohol abstinence on blood pressure: assessment by 24-h ambulatory blood pressure monitoring. Hypertension 1999; 33: 653-657.

79 McFadden CB, Brensinger CM, Berlin JA, Townsend RR. Systematic review of the effect of daily alcohol intake on blood pressure. Am J Hypertens 2005; 18: 276-286.

80 Kawano Y, Pontes CS, Abe H, Takishita S, Omae T. Effects of alcohol consumption and restriction on home blood pressure in hypertensive patients: serial changes in the morning and evening records. Clin Exp Hypertens 2002; 24: 33-39.

81 Strickland JA, Wooles WR. Blood ethanol level and physiologic measurements during ethanol-induced hypertension. Alcohol 1989; 6: 109-114.

82 Vasdev S, Sampson CA, Prabhakaran VM. Platelet free calcium and vascular calcium uptake in ethanol-induced hypertensive rats. Hypertension 1991; 18: 116-122.

83 Puddey IB, Burke V, Croft K, Beilin LJ. Increased blood pressure and changes in membrane lipids associated with chronic ethanol treatment of rats. Clin Exp Pharmacol Physiol 1995; 22: 655-657.

84 Harada H, Kitazaki K, Tsujino T, Watari Y, Iwata S, Nonaka H, Hayashi T, Takeshita T, Morimoto K, Yokoyama M. Oral taurine supplementation prevents the development of ethanol-induced hypertension in rats. Hypertens Res 2000; 23: 277-284.

85 Abdel-Rahman AA. Alcohol abolishes the hypotensive effect of clonidine in spontaneously hypertensive rats. Hypertension 1994; 24: 802-807.

86 Howe PRC, Rogers PF, Smith RM. Antihypertensive effect of alcohol in spontaneously hypertensive rats. Hypertension 1989; 13: 607-611.

87 Hatton DC, Bukoski RD, Edgar S, McCarron DA. Chronic alcohol consumption lowers blood pressure but enhances vascular contractility in Wistar rats. J Hypertens 1992; 10: 529-537.

88 Beilin LJ, Hoffmann P, Nilsson H, Skarphedinsson J, Folkow B. Effect of chronic ethanol consumption upon cardiovascular reactivity, heart rate and blood pressure in spontaneously hypertensive and Wistar-Kyoto rats. J Hypertens 1992; 10: 645-650.

89 El-Mas MM, Abdel-Rahman AA. Ovariectomy alters the chronic hemodynamic and sympathetic effects of ethanol in radiotelemetered female rats. Clin Exp Hypertens 2000; 22: 109-126.

90 Crandall DL, Ferraro GD, Lozito RJ, Cervoni P, Clark LT. Cardiovascular effects of intermittent drinking: assessment of a new animal model of human alcoholism. J Hypertens 1989; 7: 683-687.

91 Capasso JM, Li P, Guideri G, Anversa P. Left ventricular dysfunction induced by chronic alcohol ingestion in rats. Am J Physiol 1991; 261: H212-H219.

92 Schlicht I, Falk S, Krossin A, Mohnhaupt A. Lifetime prolongation in voluntary alcoholconsuming rats (SHR) treated with clofibrate. Alcohol 1992; 9: 139-148.

93 Ishikawa J, Kario K, Eguchi K, Morinari M, Hoshide S, Ishikawa S, Shimada K. Regular alcohol drinking is a determinant of masked morning hypertension detected by home blood pressure monitoring inmmedicated hypertensive patients with well controlled clinic blood pressure: The Jichi Morning Hypertension Research (J-MORE) study. Hypertens Res 2006; 29: 679-686.

94 Kawano Y, Abe H, Kojima S, Takishita S, Omae T. Interaction of alcohol and an á blocker on ambulatory blood pressure in patients with essential hypertension. $A m \mathrm{~J}$ Hypertens 2000; 13: 307-312.

95 Bailey DG, Spence JD, Edgar B, Bailiff CD, Arnold JMO. Ethanol enhances the hemodynamic effects of felodipine. Clin Invest Med 1989; 12: 357-362.

96 Kawano Y, Abe H, Kojima S, Yoshimi H, Sanai T, Kimura G, Matsuoka H, Takishita S, Omae T. Different effects of alcohol and salt on 24-h blood pressure and heart rate in hypertensive patients. Hypertens Res 1996; 19: 255-261.

97 Kawano Y, Okuda N, Minami J, Takishita S, Omae T. Effects of a low energy diet and an insulin-sensitizing agent on ambulatory blood pressure in overweight hypertensive patients. J Hypertens 2000; 18: 1451-1455.

98 Kawano Y. Role of blood pressure monitoring in non-pharmacological management of hypertension. Blood Press Monit 2002; 7: 51-54.

99 Walsh CR, Larson MG, Evans JC, Djousse L, Ellison C, vasan RS, Levy D. Alcohol consumption and risk of congestive heart failure in the Framingham Heart Study. Ann Intern Med 2002; 136: 181-191.

100 Bryson CL, Mukamal KJ, Mittleman MA, Fried LP, Hirsch CH, Kitzman DW, Siscovick DS. The association of alcohol consumption and incident heart failure: the Cardiovascular Health Study. J Am Coll Cardiol 2006; 48: 305-311.

101 Klatsky AL, Chartier D, Udaltsova N, Gronningen S, Brar S, Friedman GD, Landstrom RJ. Alcohol drinking and risk of hospitalization for heart failure with and without associated coronary artery disease. Am J Cardiol 2005; 96: 346-351.

102 Cohen EJ, Klatsky AL, Armstrong A. Alcohol use and supraventricular arrhythmia. Am J Cardiol 1988; 62: 971-973.

103 Frost L, Vestergaard P. Alcohol and the risk of atrial fibrillation or flutter. Arch Intern Med 2004; 164: 1993-1998.

104 Conen D, Tedrow UB, Cook NR, Moorthy MV, Buring JE, Albert CM. Alcohol consumption and risk of incident atrial fibrillation in women. JAMA 2008; 300: 2489-2496.

105 Boffetta P, Garfinkel L. Alcohol drinking and mortality among men enrolled in an American Cancer Society prospective study. Epidemiology 1990; 1: 342-348.

106 Rimm EB, Giovanucci EL, Willett WC, Colditz DA, Ascherio A, Rosner B, Stampfer MJ. Prospective study of alcohol consumption and risk of coronary disease in men. Lancet 1991; 338: 464-468.

107 Rimm EB, Williams P, Fosher K, Criqui M, Stampfer MJ. Moderate alcohol intake and lower risk of coronary heart disease: meta-analysis of effects on lipids and haemostatic factors. Br Med J 1999; 319: 1523-1528.

108 Beulens JWJ, Rimm EB, Ascherio A, Spiegelman D, Hendriks HFJ, Mukamal KJ. Alcohol consumption and risk for coronary heart disease among men with hypertension. Ann Intern Med 2007; 146: 10-19.
109 Vliegenhart R, Oei HS, van den Elzen APM, van Rooij FJA, Hofman A, Oudkerk M, Witteman JCM. Alcohol consumption and coronary calcification in a general population. Arch Intern Med 2004, 164: 2355-2360.

110 Ikehara S, Iso H, Toyoshima H, Date C, Yamamoto A, Kikuchi S, Kondo T, Watanabe Y, Koizumi A, Wada Y, Inaba Y, Tamakoshi A. Japan Collabrative Cohort Study Group: alcohol consumption and mortality from stroke and coronary heart disease among Japanese men and women: the Japan Collaborative Cohort Study. Stroke 2008; 39: 2936-2942.

111 Langer RD, Criqui MH, Reed DM. Lipoproteins and blood pressure as biological pathways for effect of moderate alcohol consumption on coronary heart disease. Circulation 1992; 85: 910-915.

112 Albert MA, Glynn RJ, Ridker PM. Alcohol consumption and plasma concentration of Creactive protein. Circulation 2003; 107: 443-447.

113 Renaud SC, Gueguen R, Siest G, Salamon R. Wine, beer, and mortality in middle-aged men from eastern France. Arch Intern Med 1999; 159: 1865-1870.

114 Di Castelnuovo A, Rotondo S, lacoviello L, Donati MB, de Gaetano G. Meta-analysis of wine and beer consumption in relation to vascular risk. Circulation 2002; 105 : 2836-2844.

115 Rimm EB, Klatsky A, Grobbee D, Stampfer MJ. Review of moderate alcohol consumption and reduced risk of coronary heart disease: is the effect due to beer, wine, or spirits? Br Med J 1996; 312: 731-736.

116 Camargo Jr CA. Moderate alcohol consumption and stroke: the epidemiologic evidence. Stroke 1989; 20: 1611-1626.

117 Iso H, Baba S, Mannami T, Sasaki S, Okada K, Konishi M, Tsugane S. Alcohol consumption and risk of stroke among middle-aged men: the JPHC study Cohort I. Stroke 2004; 35: 1124-1129.

118 Elkand MSV, Sciacca R, Baden-Albela B, Rundek T, Paik MC, Sacco RF. Moderate alcohol consumption reduces risk of ischemic stroke: the Northern Manhattan Study. Stroke 2006; 37: 13-19.

119 Djousse L, Ellison C, Beiser A, Scaramucci A, D'Agostino RB, Wolf PA. Alcohol consumption and risk of ischemic stroke: the Framingham Study. Stroke 2002; 33: 907-912.

120 Mukamal KJ, Ascherio A, Mittelman MA, Conigrave KM, Camargo Jr CA, Kawachi I, Stampfer MJ, Willett WC, Rimm EB. Alcohol and risk for ischemic stroke in men: the role of drinking patterns and usual beverage. Ann Intern Med 2005; 142: 11-19.

121 Mukamal KJ, Longstreth Jr WT, Mittelman MA, Crum RM, Siscovick DS. Alcohol consumption and subclinical findings on magnetic resonance imaging of the brain in older adults: the Cardiovascular Health Study. Stroke 2001; 32: 1939-1946.

122 Ding J, Eigenbrodt ML, Mosley Jr TH, Hutchinson RG, Folsom AR, Harris TB, Nieto FJ. Alcohol intake and cerebral abnormalities on magnetic resonance imaging in a community-based population of middle-aged adults: the Atherosclerosis Risk in Communities (ARIC) Study. Stroke 2004; 35: 16-21.

123 Jepson RG, Fowkes FG, Donnan PT, Housley E. Alcohol intake as a risk factor for peripheral artery disease in the general population in the Edinburgh Artery Study. Eur J Epidemiol 1995; 11: 9-14.

124 Camargo Jr CA, Stampfer MJ, Glynn RJ, Gaziano M, Manson JE, Goldhaber SZ, Hennekens $\mathrm{CH}$. Prospective study of moderate alcohol consumption and risk of peripheral artery disease in US male physicians. Circulation 1997; 95: 577-580.

125 Djousse L, Levy D, Murabito JM, Cupples LA, Ellison PC. Alcohol consumption and risk of intermittent claudication in the Framingham Heart Study. Circulation 2000; 102: 3092-3097.

126 Vliegenthart R, Gleijinse JM, Hofman A, Meijer WT, van Rooij FJA, Grobbee DE, Witteman JCM. Alcohol consumption and risk of peripheral arterial disease. Am J Epidemiol 2002; 155: 332-338.

127 Bagousslavsky J, Van Melle G, Despland PA, Regli F. Alcohol consumption and carotid atherosclerosis in the Lausanne Stroke Registry. Stroke 1990; 21: 715-720.

128 Demirovic J, Nabulsi A, Folsom AR, Carpenter MA, Szklo M, Sorlie PD, Barnes RW. Alcohol consumption and ultrasonographycally assessed carotid artery wall thickness and distensibility. Circulation 1993; 88: 2787-2793.

129 Kiechl S, Willeit J, Egger G, Oberhollenzer M, Aichner F. Alcohol consumption and carotid atherosclerosis: evidence of dose-dependent atherogenic and antiatherogenic effects: results from the Bruneck Study. Stroke 1994; 25: 1593-1598.

130 Schminke U, Luedemann J, Berger K, Alie D, Mitusch R, Wood WG, Jachinski A, Barnow $\mathrm{S}$, John U, Kessler C. Association between alcohol consumption and subclinical carotid atherosclerosis: the Study of Health in Pomerania. Stroke 2005; 36: 1746-1752.

131 Sierksma A, Muller M, van der Schouw YT, Grobbee DE, Hendriks HFJ, Bots ML. Alcohol consumption and arterial stiffness in men. J Hypertens 2004; 22: 357-362.

132 van den Elzen AP, Sierksma A, Oren A, Vos LE, Witteman JC, Grobbee DE, Handriks $\mathrm{HF}$, Uitarwaal CS, Bots ML. Alcohol intake and aortic stiffness in young men and women. J Hypertens 2005; 23: 731-735.

133 Kurihara T, Tomiyama $\mathrm{H}$, Hashimoto $\mathrm{H}$, Yamamoto $\mathrm{Y}$, Yano E, Yamashina A. Excessive alcohol intake increases the risk of arterial stiffening in men with normal blood pressure. Hypertens Res 2004; 27: 669-673.

134 Stampfer MJ, Hu FB, Manson JE, Rimm EB, Willett WC. Primary prevention of coronary heart disease in women through diet and lifestyle. N Engl J Med 2000; 343: 16-22.

135 Franco OH, Bonneux L, de Laet C, Peeters A, Steyerberg EW, Mackenbach JP. The polymeal: a more natural, safer, and probably tastier (than polypill) strategy to reduce cardiovascular disease by more than 75\%. Br Med J 2004; 329: 1147-1150.

136 Gronbeck M, Becker U, Johansen D, Cottschau A, Schmahr P, Hein HO, Jensen G, Sorenses TIA. Type of alcohol consumed and mortality from all causes, coronary heart disease, and cancer. Ann Intern Med 2000; 133: 411-419.

137 Rehm J, Greenfield TK, Rogers JD. Average volume of alcohol consumption, patterns of drinking, and all-cause mortality: results from the US National Alcohol Survey. Am J Epidemiol 2001; 153: 64-71. 